\title{
What's Under your Feet? Analysis of Leaf Litter Invertebrate Diversity Using an Updated On-line Key
}

\section{Vanessa Muilenburg and Lori Hertel}

\author{
Hope College, Department of Biology, 35 E 12th St, Holland Michigan 49423 USA \\ (muilenburg@hope.edu; hertel@hope.edu)
}

\begin{abstract}
Invertebrates are ubiquitous inhabitants of leaf litter in forests. Because of their abundance and diversity, they are an excellent resource for answering open-ended questions about how different attributes in our environment impact animal diversity. However, visual identification of invertebrates to standard taxonomic species requires considerable knowledge of morphological traits that only entomological experts possess. Mastery of these taxonomic characters associated with each species is not practical for undergraduate courses. We present an updated electronic key that identifies invertebrate specimens to morphospecies, which are classified from other related organisms by visual appearance. Participants in this workshop examined samples of invertebrates collected from leaf litter using dissecting microscopes and then use pictures and answer basic questions in the electronic key to identify the specimens to morphospecies. The online key presented is an updated version published by Murray et al. 2002 in ABLE. The key can be assessed and used on smartphones and computers via the link: https://sites.google.com/hope.edu/leaflitterinvertebrates/home.
\end{abstract}

Keywords: invertebrate diversity, leaf litter, on-line invertebrate key

\section{Mission, Review Process \& Disclaimer}

The Association for Biology Laboratory Education (ABLE) was founded in 1979 to promote information exchange among university and college educators actively concerned with teaching biology in a laboratory setting. The focus of ABLE is to improve the undergraduate biology laboratory experience by promoting the development and dissemination of interesting, innovative, and reliable laboratory exercises. For more information about ABLE, please visit http:// www.ableweb.org/.

Advances in Biology Laboratory Education is the peer-reviewed publication of the conference of the Association for Biology Laboratory Education. Published articles and extended abstracts are evaluated and selected by a committee prior to presentation at the conference, peer-reviewed by participants at the conference, and edited by members of the ABLE Editorial Board. Published abstracts are evaluated and selected by a committee prior to presentation at the conference.

\section{Citing This Article}

Muilenburg V, Hertel L. 2020. What's under your feet? Analysis of leaf litter invertebrate diversity using an updated on-line key. Article 46 In: McMahon K, editor. Advances in biology laboratory education. Volume 41. Publication of the 41st Conference of the Association for Biology Laboratory Education (ABLE). https://doi.org/10.37590/able.v41.abs46

Compilation (C) 2020 by the Association for Biology Laboratory Education, ISBN 1-890444-17-0. All rights reserved. No part of this publication may be reproduced, stored in a retrieval system, or transmitted, in any form or by any means, electronic, mechanical, photocopying, recording, or otherwise, without the prior written permission of the copyright owner.

ABLE strongly encourages individuals to use the exercises in this volume in their teaching program. If this exercise is used solely at one's own institution with no intent for profit, it is excluded from the preceding copyright restriction, unless otherwise noted on the copyright notice of the individual chapter in this volume. Proper credit to this publication must be included in your laboratory outline for each use; a sample citation is given above. 